\title{
SUPPORTING INFORMATION \\ A Generalized Synthesis Strategy for Binderless, Free-standing \\ Anode for Lithium/Sodium Ion Battery Comprised of Metal
}

\section{Selenides@Carbon Nanofibers}

Zizhou He ${ }^{a}$,Hui Guo ${ }^{a}$, Jed D LaCoste ${ }^{a}$, Don Werder ${ }^{b, c, d}$, Derek J Durocher ${ }^{a}$, Ryan A Cook ${ }^{a}$,

Phat Truong ${ }^{e}$, Hongmei Luo ${ }^{e}$, Xiao-Dong Zhou ${ }^{*}$, Ling Fei ${ }^{* a}$

${ }^{a}$ Department of Chemical Engineering, Institute for Materials Research and Innovations, University of Louisiana at Lafayette, Lafayette, LA 70504, USA.

E-mail: xiao-dong.zhou@louisiana.edu, ling.fei@louisiana.edu

${ }^{\mathrm{b} C}$ Cornell Center for Materials Research, Cornell University, Ithaca, NY 14853, USA

${ }^{c}$ Department of Materials Science and Engineering, Cornell University, Ithaca, NY 14853, USA

${ }^{\mathrm{d}}$ Platform for the Accelerated Realization, Analysis, and Discovery of Interface Materials (PARADIM), Cornell University, Ithaca, New York 14853, USA

${ }^{e}$ Department of Chemical and Materials Engineering, New Mexico State University, Las Cruces, NM 88003, USA 


\section{Table of Contents}

1. Figure S1. Digital images of free-standing electrode..............................................S3

2. Figure S2. TGA analysis of all the MSe@CNFs samples...............................................S4

3. Figure S3. XPS spectra for FeSe@CNFs, NiSe@CNFs, and $\mathrm{Cu}_{2} \mathrm{Se} @ \mathrm{CNFs}$....................S5

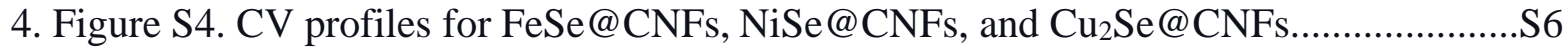

5. Figure S5. SEM images of post-cycled SnSe@CNFs electrode......................................S9

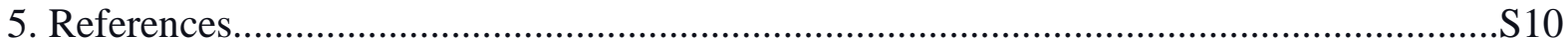



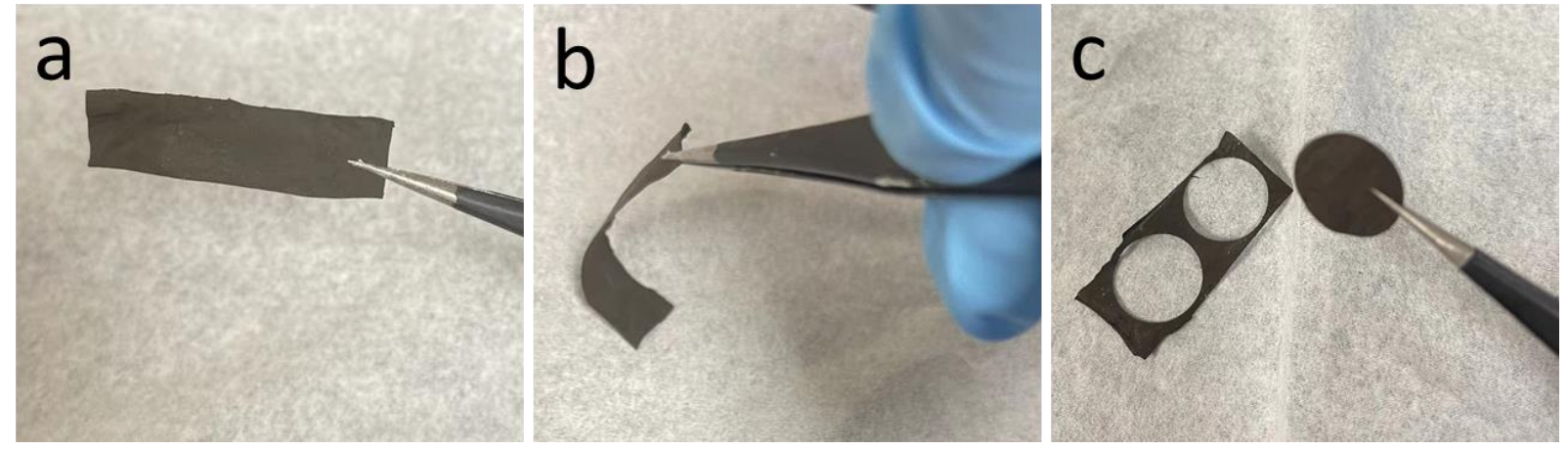

Figure S1. Digital images of (a) Free-standing fiber strip; (b) Bended strip; (c) Punched electrode. 


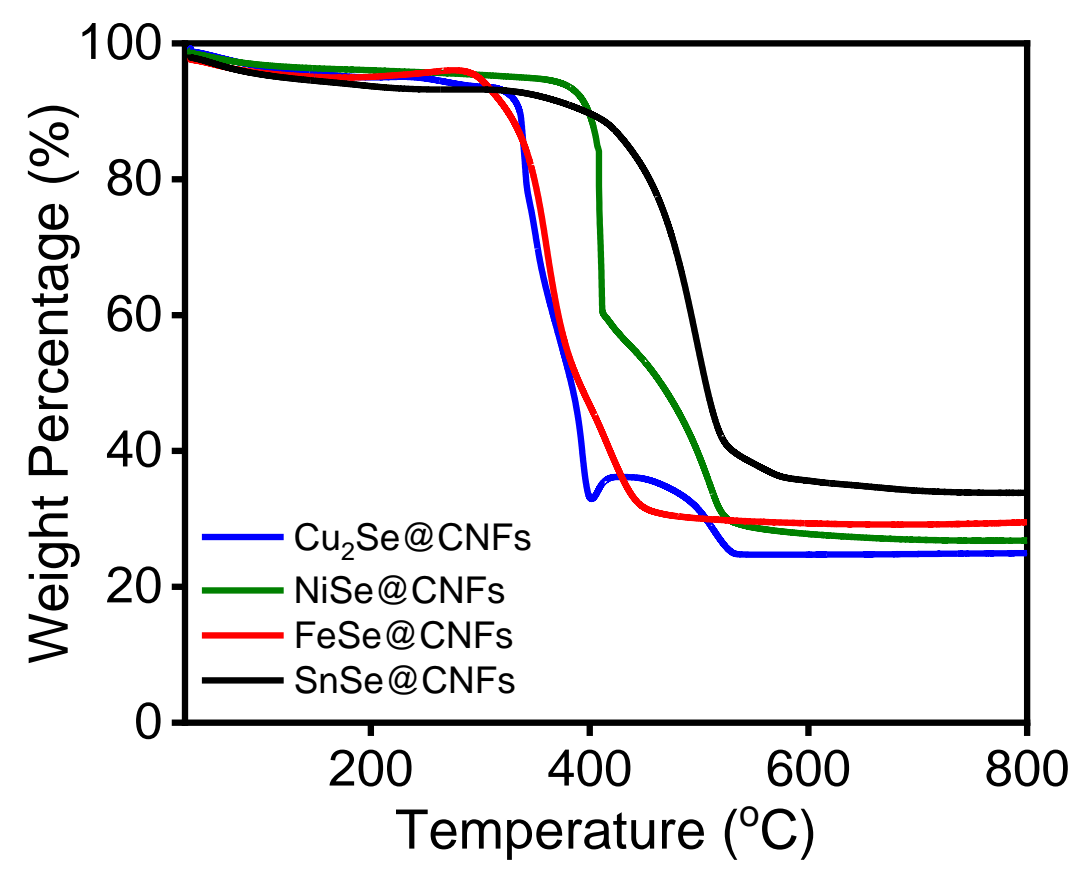

Figure S2. TGA analysis of all the MSe@CNFs samples under air atmosphere.

The TGA process involved combustion of carbon and the oxidation-reduction reaction of metal selenide:

$$
\text { Metal selenide+ Carbon nanofibers }+\mathrm{O}_{2} \rightarrow \text { Metal oxide }+\mathrm{CO}_{2}+\mathrm{SeO}_{2}
$$

The weight loss before $400^{\circ} \mathrm{C}$ is mainly due to the formation of $\mathrm{CO}_{2}$ accompanied by the sublimation of $\mathrm{SeO}_{2}\left(315^{\circ} \mathrm{C}\right)$. The sharp drop after around $400^{\circ} \mathrm{C}$ is due to the further oxidation to form intermediate phases. The final products of corresponding MSe@CNFs are $\mathrm{SnO}_{2}, \mathrm{Fe}_{2} \mathrm{O}_{3}, \mathrm{CuO}$, and $\mathrm{NiO}$, respectively. The calculated weight percentages of $\mathrm{SnSe}, \mathrm{FeSe}, \mathrm{Cu}_{2} \mathrm{Se}$ and $\mathrm{NiSe}$ are $44.38 \%, 49.84 \%, 32.31 \%$ and $49.41 \%$, respectively. 

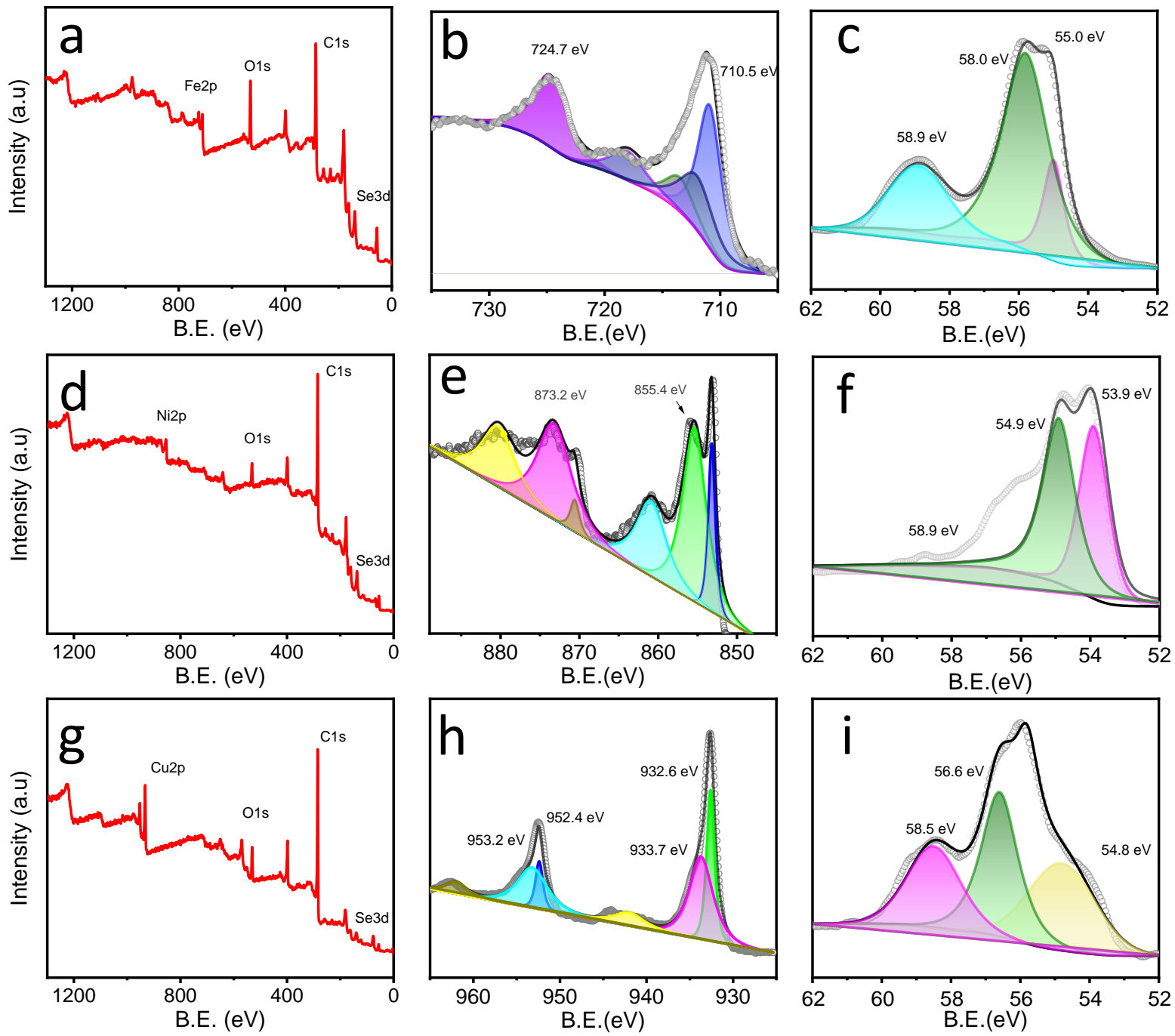

Figure S3 (a-c) Full survey, Fe 2p and Se 3d spectrum of FeSe@CNFs; (d-f) Full survey, Ni 2p and Se 3d spectrum of NiSe@CNFs; (g-h) Full survey, Cu 2p and Se 3d spectrum of $\mathrm{Cu}_{2} \mathrm{Se} @ \mathrm{CNFs}$. 

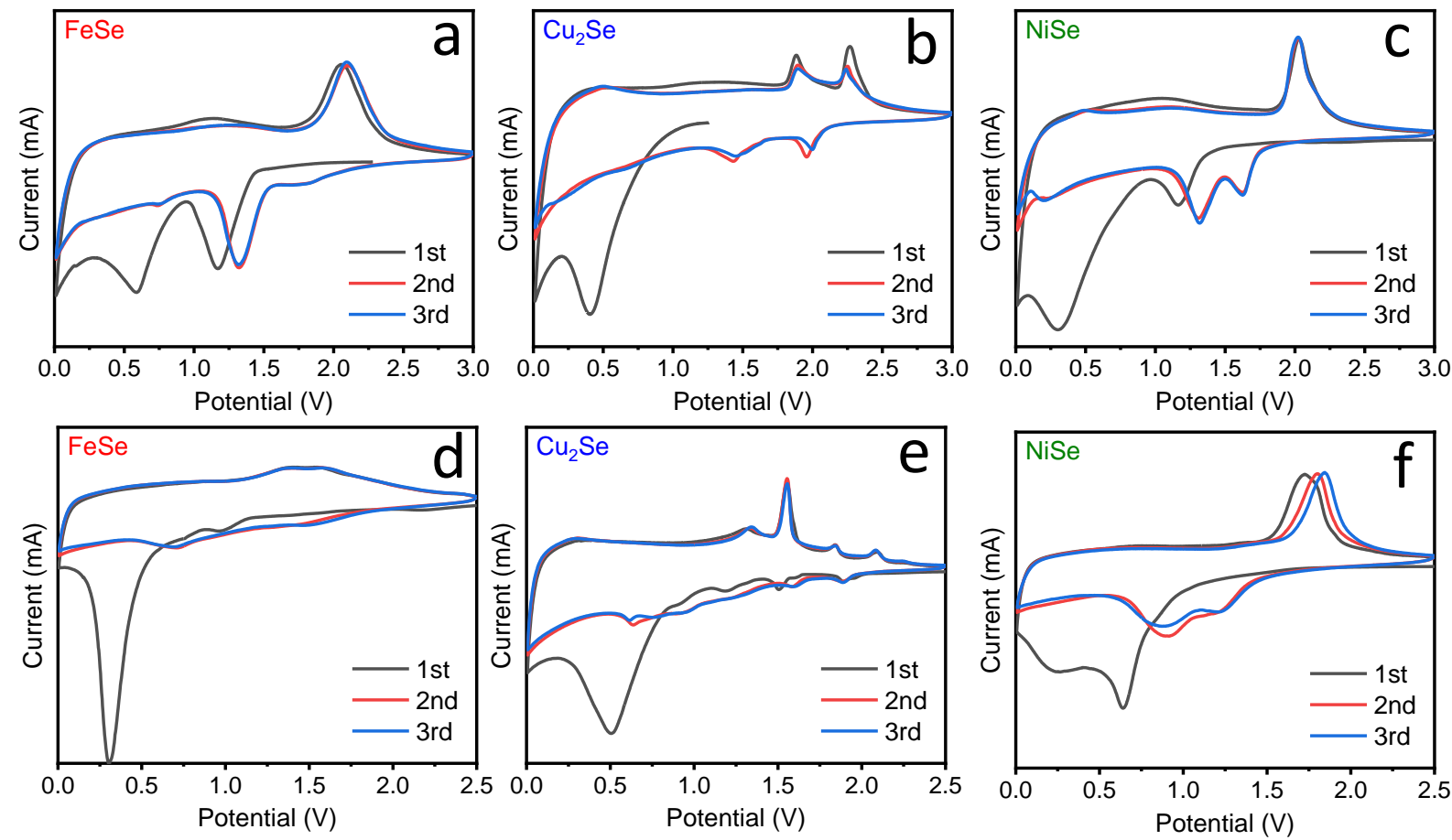

Figure S4 CV profiles of (a) FeSe@CNFs; (b) $\mathrm{Cu}_{2} \mathrm{Se} @ \mathrm{CNFs}$; (c) NiSe@CNFs electrode in LIBs, and CV profiles of (d) FeSe@CNFs; (e) $\mathrm{Cu}_{2} \mathrm{Se} @ \mathrm{CNFs}$; (f) NiSe@CNFs in SIBs

The first three CV curves of the FeSe @CNFs electrode are shown in Figure S4a. During the first sweep, the cathodic peak around $1.2 \mathrm{~V}$ can be ascribed the conversion of FeSe to metallic Fe and $\mathrm{Li}_{2} \mathrm{Se}\left(\left(\mathrm{FeSe}+2 \mathrm{Li}^{+}+2 \mathrm{e}^{-} \leftrightarrow \mathrm{Fe}+\mathrm{Li}_{2} \mathrm{Se}\right)\right)$, and the peak around $0.7 \mathrm{~V}$ is related to $\mathrm{SEI}$ formation. ${ }^{1}$ In the following cycles the cathodic peaks shift to a slightly higher potential. The anodic peak $\sim 2$ $\mathrm{V}$ corresponds to the reactions of $\mathrm{Fe}$ with $\mathrm{Li}_{2} \mathrm{Se}$ to form FeSe. ${ }^{1}$ Notably, all the peaks of the second and third cycle almost overlap, suggesting the good reversibility of the FeSe@CNFs electrode. The overall reaction mechanism of $\mathrm{Cu}_{2} \mathrm{Se} @ \mathrm{CNFs}$ can be described as $\mathrm{Cu}_{2} \mathrm{Se}+2 \mathrm{Li}^{+}+2 \mathrm{e}^{-} \leftrightarrow 2 \mathrm{Cu}+$ $\mathrm{Li}_{2} \mathrm{Se}$. As shown in Figure $\mathrm{S} 4 \mathrm{~b}$, the reduction peaks at $1.4 \mathrm{~V}$ and $2.1 \mathrm{~V}$ is due to the stepwise conversion reaction of $\mathrm{Cu}_{2} \mathrm{Se}$ to form $\mathrm{Li}_{2} \mathrm{Se}$ and $\mathrm{Cu}^{2}{ }^{2}$ while the oxidation peaks at $\sim 1.7 \mathrm{~V}$ and 2.2 $\mathrm{V}$ is due to the formation of $\mathrm{Cu}_{2} \mathrm{Se}^{3}{ }^{3}$ For NiSe@CNFs (Figure S4c), the reduction peaks at $\sim 1.2 \mathrm{~V}$ 
and $\sim 0.6 \mathrm{~V}$ of the first sweep could be assigned to the intercalation of $\mathrm{Li}^{+}$into the electrode and SEI formation. The oxidation peak at $\sim 2.1 \mathrm{~V}$ is the conversion reaction between $\mathrm{Li}_{2} \mathrm{Se}$ and $\mathrm{Ni}$, which leads to NiSe phase formation. The following oxidation peak remains at $\sim 2.1 \mathrm{~V}$, while the reduction peak shifts to a higher voltage of $\sim 1.4 \mathrm{~V}$ and $\sim 1.6 \mathrm{~V} .{ }^{4}$ The overall reaction of $\mathrm{NiSe} @ \mathrm{CNF}$ is $\mathrm{NiSe}+2 \mathrm{Li}^{+}+2 \mathrm{e}^{-} \leftrightarrow \mathrm{Ni}+\mathrm{Li}_{2} \mathrm{Se}$.

The CV measurement of FeSe@CNFs in SIBs shows in Figure S4d, the first cathodic sweep peak around $1.0 \mathrm{~V}$ could be ascribed to the reaction of sodium and FeSe and $0.3 \mathrm{~V}$ for the formation of SEI layers. From the second sweep, the cathodic peaks become broader and shift to $\sim 1.5 \mathrm{~V}$ and $\sim 0.7 \mathrm{~V}$, corresponding to the formation of intermediate product and conversion reaction between $\mathrm{Na}$ and $\mathrm{Na}_{\mathrm{x}} \mathrm{FeSe} .{ }^{5}$ The broad oxidation peak at around $1.5 \mathrm{~V}$ could be assigned to the conversion reaction from $\mathrm{Fe}$ and $\mathrm{Na}_{2} \mathrm{Se}$ to form FeSe. ${ }^{6,7}$ The overall reaction can be described as $\mathrm{FeSe}+2 \mathrm{Na}^{+}$ $+2 \mathrm{e}^{-} \leftrightarrow \mathrm{Fe}+\mathrm{Na}_{2} \mathrm{Se}$

The first three CV measurements of $\mathrm{Cu}_{2} \mathrm{Se} @ \mathrm{CNFs}$ are shown in Figure S4e. The irreversible peak at the first reduction peak $(\sim 0.5 \mathrm{~V})$ can be ascribed to the formation of the SEI layer. The other smaller peaks at $\sim 1.2 \mathrm{~V}$ and $\sim 1.5 \mathrm{~V}$ are due to the conversion of $\mathrm{Cu}_{2} \mathrm{Se}$ to $\mathrm{Na}_{2} \mathrm{Se}$ and $\mathrm{Cu}$, which shift to higher potentials in the subsequent cycles. As for the oxidation process, the peaks between $\sim 1.3 \mathrm{~V}$ and $\sim 2.0 \mathrm{~V}$ can be assigned to the sodium extraction reaction from intermediate phases to form $\mathrm{Cu}_{2} \mathrm{Se}^{8}{ }^{8}$ The overall reaction can be summarized as $\mathrm{Cu}_{2} \mathrm{Se}+2 \mathrm{Na}^{+}+2 \mathrm{e}^{-} \leftrightarrow 2 \mathrm{Cu}+\mathrm{Na}_{2} \mathrm{Se}$. The reaction can be further detailed into a multi-step reactions: $\mathrm{Cu}_{2} \mathrm{Se}+\mathrm{Na}^{+}+\mathrm{e}^{-} \rightarrow \mathrm{Na}_{\mathrm{x}} \mathrm{CuSe}+\mathrm{Cu}$, $\mathrm{Na}_{x} \mathrm{CuSe}+(1-\mathrm{x}) \mathrm{Na}^{+}+(1-\mathrm{x}) \mathrm{e}^{-} \rightarrow \mathrm{NaCuSe}, \mathrm{NaCuSe}+\mathrm{Na}^{+}+\mathrm{e}^{-} \rightarrow \mathrm{Cu}+\mathrm{Na}_{2} \mathrm{Se}$ for discharging processes, and $\mathrm{Cu}+\mathrm{Na}_{2} \mathrm{Se} \rightarrow \mathrm{NaCuSe}+\mathrm{Na}^{+}+\mathrm{e}^{-}, \mathrm{NaCuSe}+\mathrm{Cu} \rightarrow \mathrm{Cu}_{2} \mathrm{Se}+\mathrm{Na}^{+}+\mathrm{e}^{-}$for charging processes. ${ }^{9}$ Figure S4f shows the first three CV cycles of NiSe@CNFs. The reduction peak around $0.7 \mathrm{~V}$ during the first cycle represents SEI formation as well as the reaction with sodium to form $\mathrm{Na}_{2} \mathrm{Se}$ and metallic 
Ni. The oxidation peak at $\sim 1.75 \mathrm{~V}$ corresponds to the extraction of $\mathrm{Na}^{+} .{ }^{10}$ The peaks shift to a slightly higher position after the first cycle. The overall reaction can be concluded with: NiSe+ $2 \mathrm{Na}^{+}+2 \mathrm{e}^{-} \leftrightarrow \mathrm{Ni}+\mathrm{Na}_{2} \mathrm{Se}$ 


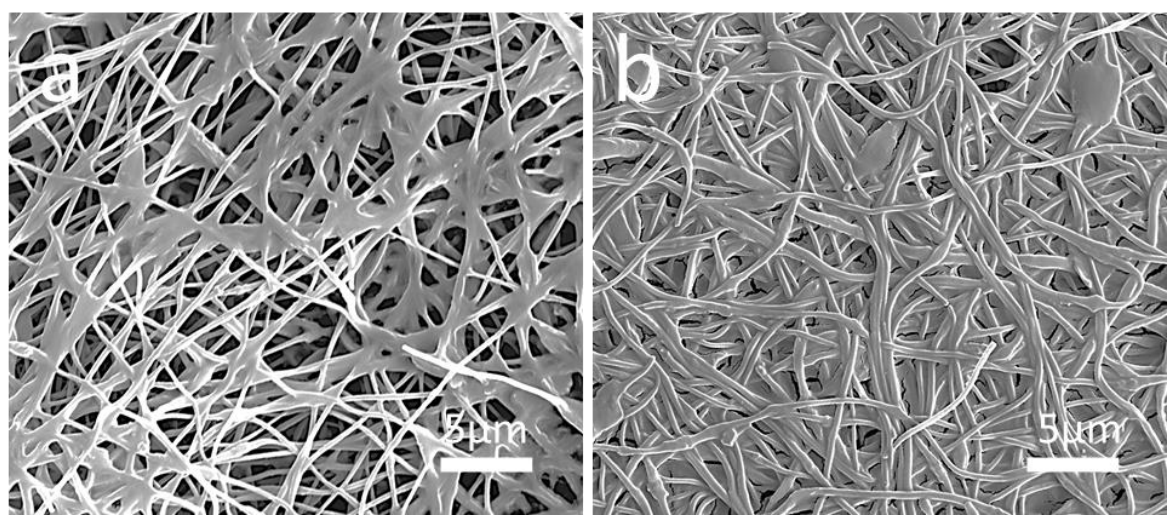

Figure S5. SEM images of SnSe@CNFs electrode after (a) 50 cycles; (b) 400 cycles at 1A/g. 


\section{References}

1. Zhong, D.; Chen, J.; Zhang, J.; Luo, Y.; Li, Z.; Cheng, L.; Chen, Y.; Wang, G.; Wang, R., The yolk-shell FeSe@C nanobox with novel synthesis and its high performance for the anode of lithium-ion batteries. Mater. Res. Express 2019, 6, 085058.

2. Li, X.; Zhang, Z.; Liu, C.; Lin, Z., Capacity increase investigation of cu $_{2}$ se electrode by using electrochemical impedance spectroscopy. Front. Chem. 2018, 6, 221.

3. Xue, M. Z.; Zhou, Y. N.; Zhang, B.; Yu, L.; Zhang, H.; Fu, Z. W., Fabrication and electrochemical characterization of copper selenide thin films by pulsed laser deposition. $J$. Electrochem. Soc. 2006, 153, A2262.

4. Zhang, Z.; Shi, X.; Yang, X., Synthesis of core-shell NiSe/C nanospheres as anodes for lithium and sodium storage. Electrochim. Acta 2016, 208, 238-243.

5. Li, J.; Zhao, J.; Tang, R.; Chen, Q.; Niu, Z.; Li, M.; Guo, C.; Su, J.; Zhang, L., Facilely fabricating fese nanoparticles embedded in N-doped carbon towards promoting sodium storage behaviors. J. Power Sources 2020, 449, 227517.

6. Wu, K.; Chen, F.; Ma, Z.; Guo, B.; Lyu, Y.; Wang, P.; Yang, H.; Li, Q.; Wang, H.; Nie, A., In situ TEM and half cell investigation of sodium storage in hexagonal FeSe nanoparticles. Chem. Commun. 2019, 55, 5611-5614.

7. Xiong, Z.; Sun, D.; Jia, X.; Zhou, J., Core/shell FeSe/carbon nanosheet-assembled microflowers with ultrahigh coulombic-efficiency and rate performance as nonpresodiate anode for sodium-ion battery. Carbon 2020, 166, 339-349. 
8. Yue, J. L.; Sun, Q.; Fu, Z. W., $\mathrm{Cu}_{2} \mathrm{Se}$ with facile synthesis as a cathode material for rechargeable sodium batteries. Chem Commun. 2013, 49 (52), 5868-70.

9. Xu, X.; Liu, J.; Liu, J.; Ouyang, L.; Hu, R.; Wang, H.; Yang, L.; Zhu, M., A general metalorganic framework (MOF)-derived selenidation strategy for in situ carbon-encapsulated metal selenides as high-rate anodes for Na-ion batteries. Adv. Funct. Mater. 2018, 28 (16), 1707573.

10. Su, C.; Ru, Q.; Cheng, S.; Gao, Y.; Chen, F.; Zhao, L.; Ling, F. C.-C., 3D pollen-scaffolded NiSe composite encapsulated by MOF-derived carbon shell as a high-low temperature anode for Na-ion storage. Compos. B. Eng. 2019, 179, 107538. 